\title{
EDITORIAL: AROUND THE WORLD AND BACK AGAIN
}

This edition of the International Review of Education was prepared with a view to publication soon after the conclusion of the Sixth International Conference on Adult Education (CONFINTEA VI) in Brazil, May 2009, coordinated on behalf of UNESCO organised by the UNESCO Institute for Lifelong Learning (UIL). As in life, however, the best-laid plans often go awry. In this case, two weeks prior to its scheduled start, the Conference was postponed because of the general global public health concerns associated with the spread of the so-called "swine flu" virus A (H1N1). Developments on CONFINTEA VI are picked up later in this Editorial. For now, though, IRE appears as originally planned.

One of the organising principles adopted in the selection of contributions to this edition was geography, in order to give representation to all five UNESCO regions (Africa; Arab States; Asia and the Pacific; Europe, North America and Israel; and Latin America and the Caribbean). In truth, this follows from IRE's overall editorial policy, as one of its roles is to reflect work from around the world, and thus to redress the usual preponderance, in academic journals, of articles from the North. However, assembling the content of IRE is not solely a matter of choosing from the available pool of submissions and engineering a regional balance. One job of the Editor is to shape each edition coherently so that it is not a random collection of apparently unconnected papers. The general unifying theme in this instance is achievement, equity and quality in schools. At first, this might seem to be quite a broad set of categorisations - and each of these itself would certainly merit at least an entire volume - yet the reader will find that common concerns and issues run throughout.

Even the rather mechanical process of creating geographical parity in the pages of $I R E$ is not necessarily a straightforward affair. A notable instance is the paucity of material from the Arab States, a subject which was discussed by IRE's Editorial Board meeting in March this year. There was a concern that the journal might be unknown or inaccessible to readers and writers of Arabic. The action taken to address this is to include, from next year, abstracts in Arabic, and similarly in Chinese. The hope is to attract more Arabic- and Chinese-speaking readers and authors. The work of our contributors will also be exposed to an audience which up to now has been largely unable to gain access to IRE. Well, that is the theory, and we will now have to see if it works in practice. We hope that, with the support of our publisher, we will be able to monitor the online usage of IRE, and that our expectations are borne out. In any case, this is a major step forward: the 
contents of the journal will, for the first time, be available in the full range of UNESCO languages (together with German).

There is a slight irony that, in fact, an article on the Arab States leads off the edition. David Chapman and Suzanne Miric ask why levels of student achievement in schools in the Middle East and North Africa tend to be lower than in other parts of the world. So, where does the problem lie? The observation is made that teachers are relatively well trained and remunerated, enjoying high levels of job security and good teacher:student ratios. The authors consider whether governments can improve educational quality merely by increasing resources and inputs, or by operating incentive systems. Perhaps, they suggest, it is only when governments incorporate the dimension of public accountability - involving parents, communities and education authorities - that such interventions have the best chance of success.

It is the precisely the greater involvement of parents and communities in the running of schools in Brazil that Bernd Reiter reviews in his article on educational equity. He examines the effect of new educational laws promoting more democratic participation in the running of public and community schools in Bahia State, and observes that these are insufficient to offset the entrenched privileges of the elite. Political opposition to the status quo can easily be sidestepped or deflected. For the majority of Bahians, poor and black, the reality is far removed from the ideals of the educational reform process.

Marie Huet-Gueye and Myriam de Léonardis analyse reasons for nonenrolment in public schools in Senegal. Only two-thirds of children eligible to enrol actually do so, despite the fact that it has been compulsory since 1990. Psychosocial factors such as parental identity are explored in order to gain fuller insights into why this should be so. The authors also discuss how "traditional" and "modern" schools shape children's attitudes.

Jeffery H. Marshall, Ung Chinna, Puth Nessay, Ung Ngo Hok, Va Savoeun, Soeur Tinon and Meung Veasna analyse data concerning student achievement in Cambodia. In so doing, the authors address the delicate balance that is required between, on the one hand, improving participation rates and, on the other, maintaining (or improving) the quality of education (as measured by student achievement). Rapid expansion in enrolment rates can have a detrimental effect on quality, as the system is placed under greater strain. To what extent is one achieved at the expense of the other?

The same kind of tension is rehearsed in the last article of this edition, albeit from a somewhat different perspective. Instead of placing the usual emphasis on poorly-performing children, Margrit Stamm and Martin Viehhauser concentrate on those who excel. Implicitly, the authors raise the question whether it is "fair" or equitable if gifted children are not developed to their full potential, by pedagogical approaches which do not cater to their particular needs. The inference is that a one-size-fits-all approach may lead to exclusion of those at the top end of the educational spectrum. Perhaps this littleexpressed view may provoke a few raised eyebrows. 
Having conducted a rapid mini-world tour in these last paragraphs, I return now to the departure lounge at the beginning of this Editorial: the postponed CONFINTEA VI. There has been unwavering commitment on the part of UNESCO, the Government of Brazil and the Governments of the State of Pará and the City of Belém to stage the Conference this year. New dates have been set: 1-4 December. Having caught their breath, colleagues at UIL can now focus over the next few months with renewed energy on organising this important gathering of adult education policymakers, researchers and practitioners from UNESCO Member States. It promises to be another interesting journey. There will be a special edition of $I R E$ devoted to the policy and practice implications of CONFINTEA VI, to be published next year. Meanwhile, of course, other work at UIL continues...

VIRMAN MAN 